\title{
Modest Exercise-Induced Increases in Testosterone Concentration Are Not Associated with Mating Strategy Change in Healthy Young Men
}

\author{
Andrew G. Thomas ${ }^{1}$ (D ) Marta Kowal ${ }^{2} \cdot$ Piotr Sorokowski $^{2} \cdot$ Agnieszka Żelaźniewicz $^{3} \cdot$ Judyta Nowak $^{3}$. \\ Sylwester Orzechowski ${ }^{2} \cdot$ Blair T. Crewther ${ }^{4}$
}

Received: 18 August 2020 / Revised: 4 January 2021 / Accepted: 6 January 2021 / Published online: 13 January 2021

(c) The Author(s) 2021

\begin{abstract}
Research has demonstrated that increases in testosterone (T) concentration can affect the expression of behaviours and preferences that are typical of high mating effort. However, little research has considered whether such $\mathrm{T}$ increases affect mating strategy more generally and whether this is achievable using a physical intervention. In this pilot study, we examined whether exercise-induced changes in T covary with, or predict, changes in male mating strategy. Healthy young men $(N=94)$ completed a measure of short- and long-term relationship preference, before and after a series of short cycling sprints. Salivary $\mathrm{T}$ was measured pre- and post-exercise, along with salivary cortisol (C), which is known to moderate some behavioural effects of T. A significant group-level increase in T was observed, though this was smaller than anticipated $(\sim 10 \%, d=0.27)$ with substantial intragroup variation. No group-level change in $\mathrm{C}$ or mating preferences emerged. Testosterone change did not significantly predict a change in short- or long-term mating preference from baseline, even with inclusion of $\mathrm{C}$ change as a moderator. The current findings suggest that modest exercise-induced increases in $\mathrm{T}$ concentration have little impact on male mating strategies. Pharmaceutical interventions, which produce larger and more consistent $\mathrm{T}$ increases, may be required to observe mating strategy change.
\end{abstract}

Keywords Testosterone $\cdot$ Cortisol $\cdot$ Mating strategies $\cdot$ Conditional strategies $\cdot$ Mate choice

\section{Introduction}

A large body of evidence suggests that testosterone (T) mediates the expression of mating effort in humans and other species (Gray et al. 2020). Testosterone fluctuates in response to evolutionary salient social cues (e.g., interacting with mates, competitors, and offspring; Zilioli and Bird 2017), and this T reactivity is moderated by many situational and personal factors. Additionally, a wealth of indirect evidence has linked $\mathrm{T}$ to the expression of

Andrew G. Thomas

research@agthomas.net

Psychology Department, Swansea University, Swansea, UK

2 Institute of Psychology, University of Wroclaw, Wroclaw, Poland

3 Department of Human Biology, University of Wroclaw, Wroclaw, Poland

4 Institute of Sport - National Research Institute, Warsaw, Poland behaviours and desires typical of a short-term reproductive strategy. For example, some studies have reported a decline in men's baseline $\mathrm{T}$ as they become pair-bonded and start a family (Gray et al. 2006; Grebe et al. 2019b), while others report positive relationships between acute $\mathrm{T}$ changes and preferences for facial femininity, aggression, and sexual displays (Bird et al. 2016; Kilduff et al. 2013; Ronay and von Hippel 2010).

A recent trend in evolutionary psychology has seen a shift of focus from examining the impact of evolutionarily relevant cues on mate preferences, perhaps within a specific mating context, to mating strategy activation itself (e.g., preference for short-term over long-term mating; Al-Shawaf et al. 2019; Arnocky et al. 2016; Thomas and Stewart-Williams 2018). This research is important because general strategy change may be an antecedent to the specific changes in mating preferences observed in previous studies, which are often more typical of one mating strategy over the other. However, to date, no study has investigated whether $\mathrm{T}$ concentrations covary with, or predict, general mating strategy. 
A common method used to examine how circulating $\mathrm{T}$ rapidly affects behaviour is $\mathrm{T}$ administration, typically a single dose via a nasal spray or transdermal gel. This approach can elevate $\mathrm{T}$ in neutral contexts that would not normally generate a hormonal response. Such research has revealed positive associations between $\mathrm{T}$ and impulsive decision making, risk taking, empathy, and aggression (Nave et al. 2018; Nave et al. 2017; for a review, see Zilioli and Bird 2017) and, in the domain of mate preferences, enhanced male preference for facial femininity within short-term, but not long-term, mating contexts (Bird et al. 2016). However, $\mathrm{T}$ administration studies can be ethically problematic and restrictive for populations where $\mathrm{T}$ is considered a controlled substance. Physical exercise offers an alternative way to enhance $T$ release. Sprint-type exercise, for instance, can elevate $\mathrm{T}$ by up to $25 \%$ in healthy, untrained men (Crewther et al. 2014). This rise is smaller than that caused by pharmacological interventions but is less ethically problematic and provides greater ecological validity. We see no special adaptive relationship between exercise and mating. Rather, it is a means of generating an acute $\mathrm{T}$ rise and observing the subsequent impact on mating strategy.

In this pilot study, we evaluated whether sprint exerciseinduced changes in $\mathrm{T}$ concentrations can predict state preference for short-term and long-term mating. We examined these preferences separately in light of recent evidence that mating strategies appear to be activated independently (Thomas and Stewart-Williams 2018), and expected $\mathrm{T}$ to covary with short-term interest rather than long-term interest, due to the clear links between $\mathrm{T}$ and mating effort in the extant literature (Gray et al. 2020). There is evidence that the behavioural effects of $\mathrm{T}$ are moderated by cortisol (C) availability (Mehta and Josephs 2010; Grebe et al. 2019a) such that a stronger link occurs at a low, rather than a high, $\mathrm{C}$ concentration (e.g., dual-hormone hypothesis). Thus, both $\mathrm{T}$ and $\mathrm{C}$ were measured in this work. Our hypotheses were that increases in $\mathrm{T}$ concentration would be positively associated with short-term, but not long-term, relationship preferences $(\mathrm{H} 1)$ and that these effects would be strongest at a low $\mathrm{C}$ level, compared with a high $\mathrm{C}$ level $(\mathrm{H} 2)$.

\section{Method}

\section{Participants}

Ninety-six heterosexual men $\left(M_{\text {age }}=21.3, S D=1.80\right)$ of Polish nationality were recruited from a university population through advertising on social media (e.g., Facebook groups), personal communications, and oral invitations during classes. The participants were students involved in physical activity courses and thus, were considered healthy and physically fit with an average body mass index (BMI) of $23.96(S D=2.85)$.
All men volunteered to participate without compensation, and they provided written informed consent. Ethical approval was granted by the Ethics Committee at the Institute of Psychology, University of Wroclaw. The hormonal data in this study are part of a published dataset (Kowal et al. 2020), but here we present different aims and dependent variables to prevent any replication of results.

\section{Materials and Procedure}

\section{Study Design}

The study cohort was assessed using a single-group, preto post-test design. Individual testing was completed in 60-70 min, and all assessments were conducted within a 4-h window (07:00-11:00) with an average start time of $08: 42(S D=00: 40)$. To account for the early morning $C$ surge, all participants were required to be awake for at least $60 \mathrm{~min}$ before their scheduled test, resulting in the first saliva collection at least $75 \mathrm{~min}$ (but generally $90-180 \mathrm{~min}$ ) from waking. After providing informed consent and completing demographic forms, participants had their relationship preferences measured (see below). Next, a saliva sample was taken before completing a 5 min warm-up (60 rpm with a 2-kg resistance) on a Monark 894E cycle ergometer (Sweden). The exercise intervention involved a series of maximal cycling sprints $(5 \times 10 \mathrm{~s}$ trials $)$ with a resistance set at $7.5 \%$ of each participant's body weight (Crewther et al. 2014, 2017). Each trial was followed by $50 \mathrm{~s}$ of recovery (slow cycling at $60 \mathrm{rpm}$ with no resistance). Heart rate (HR) was recorded at baseline and during the sprint task, as a measure of physiological activity, a potential covariate given the impact of physical exercise on multiple physiological systems. A second saliva sample was taken 12 min after exercise, after which relationship preferences were measured for a second time.

\section{Measuring Mating Strategy}

A modified version of the 'Snog, Marry, Avoid' (SMA) task was used to measure relationship preferences. The SMA task was designed to capture within-person change in mating strategy within the same experimental session and has proven sensitive enough to capture change in relationship preferences after brief experimental interventions (Thomas and Stewart-Williams 2018). Participants began by viewing pictures of women, individually and in a random order, on a computer screen. For each picture, they indicated whether they found the person attractive using 'Yes' or 'No' buttons. There were 200 pictures in the database, sourced from the public domain, though the selection task terminated once an individual picked 50 women they found attractive. These pictures were randomly divided into two sets of 25 (1 set 
Table 1 A pre-post comparison of the hormonal, physiological, and mate preference measures used in the study

\begin{tabular}{|c|c|c|c|c|c|c|c|}
\hline & \multicolumn{2}{|c|}{ Pre-exercise } & \multicolumn{2}{|c|}{ Post-exercise } & \multirow[b]{2}{*}{$t$} & \multirow[b]{2}{*}{$p$} & \multirow[b]{2}{*}{$d$} \\
\hline & $M$ & $S D$ & $M$ & $S D$ & & & \\
\hline Testosterone (pg/ml) & 133.7 & 55.1 & 146.1 & 58.2 & 2.65 & 0.01 & 0.27 \\
\hline Cortisol (ng/ml) & 8.10 & 1.70 & 7.91 & 1.83 & -1.39 & 0.17 & -0.14 \\
\hline Heart Rate (bpm) & 68.4 & 9.58 & 166.0 & 12.2 & 69.5 & $<0.01$ & 7.10 \\
\hline Short-term mating interest & 4.60 & 1.31 & 4.54 & 1.35 & -0.71 & 0.48 & -0.07 \\
\hline Long-term mating interest & 4.06 & 1.08 & 3.99 & 1.18 & -0.97 & 0.34 & -0.10 \\
\hline Attractiveness ratings & 5.15 & 0.89 & 5.06 & 1.04 & -1.47 & 0.14 & -0.15 \\
\hline
\end{tabular}

each for pre- and post-exercise). At baseline, the participants revisited the first set of pictures and were asked to indicate how interested they were in a long-term (LT) and short-term (ST) relationship with each (both anchored from $1-N o t$ at all interested to 7-Very interested). Participants also indicated how attractive they found the person (from 1-Not at all to 7-Very much so). To account for the effects of unfamiliarity and current relationship status, they were asked to imagine that they were single, open to a new relationship, and had met each women once or twice through friends when responding to the questions. This version of the SMA task deviated from the original in two ways. First, it allowed participants to pick photographs for themselves rather than from a pre-assembled set. Second, they responded on a scale rather than by forced choice. Pilot work revealed that these modifications had little impact on instrument sensitivity to preference change.

\section{Hormone Analyses}

Saliva samples $(\sim 2 \mathrm{~mL})$ were collected in sterile containers using a passive drool technique. To avoid contamination, the participants were required to avoid eating, drinking (except water), or smoking for $2 \mathrm{~h}$ before sampling. Samples were stored at $-17{ }^{\circ} \mathrm{C}$ and assayed within a week. After thawing and centrifugation, the samples were assayed in duplicate using enzyme-linked immunoassay kits (DEMEDITEC). The T kits had a lower sensitivity of $2.2 \mathrm{pg} / \mathrm{mL}$, an intra-assay $\mathrm{CV}$ of $<9.7 \%$, and an inter-assay $\mathrm{CV}$ of $<9.9 \%$. For the $\mathrm{C}$ kits, the corresponding values were $0.014 \mathrm{ng} / \mathrm{mL},<6.8 \%$, and $<9.4 \%$, respectively.

\section{Statistical Analyses}

To assess the impact of sprint exercise on each variable, we evaluated the pre- to post-exercise changes in T, C, $\mathrm{ST}$, and LT preferences using paired $t$ tests. Both T and C were $\log$-10 transformed before analysis to approximate normality and reduce non-uniformity bias, though untransformed means are reported to aid interpretation. Cohen's $d$ is reported as an effect size statistic. To evaluate the hormonal influence on state relationship preferences, we employed a 3-step hierarchical regression procedure with ST and LT preference changes entered as dependent variables in separate models. In Step 1, we entered age, BMI, and HR change into the model as covariates, before adding the $\mathrm{T}$ and $\mathrm{C}$ changes in Step 2, and the $\mathrm{T}$ change $\times \mathrm{C}$ change interaction in Step 3. The model residuals met all assumptions of normality. Statistical significance was set at an alpha level of 0.05 .

\section{Results}

The cycle sprint intervention led to a marked increase in $\mathrm{HR}$ and a modest increase in $\mathrm{T}$, both statistically significant, but no change in $\mathrm{C}$ concentration (Table 1). Two participants who completed the exercise intervention were unable to find 50 women that they found attractive from the database at the start of the SMA task, and so were excluded from further analysis. The final sample of 94 men showed reasonable interest in both short-term $(M=4.60, S D=1.31)$ and long-term relationships $(M=4.06, S D=1.08)$, though they had a clear preference for the former over the latter $(t(93)=3.95, p<0.001, d=0.41)$. No consistent change in relationship preferences were observed after exercise, and the attractiveness judgements of the two sets of women used in the SMA task were similar.

The regression models are shown in Table 2. After controlling for variables in Step 1, neither the $\mathrm{T}$ change nor its interaction with $\mathrm{C}$ were significant predictors of state short-term relationship preference. There was a marginal effect of C change in Step $2(p=0.05)$, such that shortterm mating interest decreased as $\mathrm{C}$ increased. Regarding state long-term preference, we found no significant effects of any hormonal predictor in Steps 1 and 2. Sensitivity analyses were performed (on both outcomes) by repeating Step 3 without covariates; only the hormonal variables were entered in a single step (Step 4). This approach did 
Table 2 Regression models predicting pre- to post-exercise change in short-term and long-term relationship interest from corresponding changes in testosterone and cortisol

\begin{tabular}{|c|c|c|c|c|c|c|}
\hline & \multicolumn{3}{|l|}{ Change in short-term interest } & \multicolumn{3}{|l|}{ Change in long-term interest } \\
\hline & $B$ & $S E$ & $p$ & $B$ & $S E$ & $p$ \\
\hline \multicolumn{7}{|l|}{ Step 1} \\
\hline Age & 0.12 & 0.08 & 0.13 & 0.05 & 0.08 & 0.55 \\
\hline$B M I$ & 0.03 & 0.08 & 0.70 & 0.10 & 0.08 & 0.21 \\
\hline$\Delta H R$ & 0.01 & 0.07 & 0.89 & -0.03 & 0.07 & 0.73 \\
\hline Model: & $F(3,90)=1.015, p=0.39, R^{2}=0.03$ & & & $F(3,90)=0.904, p=0.44, R^{2}=0.03$ & & \\
\hline \multicolumn{7}{|l|}{ Step 2} \\
\hline Age & 0.13 & 0.08 & 0.09 & 0.05 & 0.08 & 0.54 \\
\hline$B M I$ & 0.04 & 0.08 & 0.60 & 0.09 & 0.08 & 0.25 \\
\hline$\Delta H R$ & 0.04 & 0.08 & 0.57 & -0.01 & 0.08 & 0.92 \\
\hline$\Delta T$ & 0.09 & 0.08 & 0.26 & -0.05 & 0.08 & 0.49 \\
\hline$\Delta C$ & -0.16 & 0.08 & 0.05 & -0.04 & 0.08 & 0.61 \\
\hline Model: & $F(5,88)=1.502, p=0.20, R^{2}=0.08$ & & & $F(5,88)=0.742, p=0.59, R^{2}=0.04$ & & \\
\hline \multicolumn{7}{|l|}{ Step 3} \\
\hline Age & 0.13 & 0.08 & 0.11 & 0.06 & 0.08 & 0.47 \\
\hline$B M I$ & 0.04 & 0.08 & 0.61 & 0.09 & 0.08 & 0.24 \\
\hline$\Delta H R$ & 0.05 & 0.08 & 0.53 & -0.02 & 0.08 & 0.81 \\
\hline$\Delta T$ & 0.09 & 0.08 & 0.25 & -0.06 & 0.08 & 0.45 \\
\hline$\Delta C$ & -0.15 & 0.09 & 0.09 & -0.07 & 0.08 & 0.44 \\
\hline$\Delta T \times \Delta C$ & 0.03 & 0.06 & 0.64 & -0.05 & 0.06 & 0.38 \\
\hline Model: & $F(6,87)=1.276, p=0.28, R^{2}=0.08$ & & & $F(6,87)=0.747, p=0.61, R^{2}=0.05$ & & \\
\hline \multicolumn{7}{|l|}{ Step 4} \\
\hline$\Delta T$ & 0.08 & 0.08 & 0.32 & -0.08 & 0.08 & 0.33 \\
\hline$\Delta C$ & -0.12 & 0.08 & 0.17 & -0.05 & 0.08 & 0.52 \\
\hline$\Delta T \times \Delta C$ & 0.04 & 0.06 & 0.52 & -0.04 & 0.06 & 0.49 \\
\hline Model: & $F(3,90)=1.775, p=0.14, R^{2}=0.07$ & & & $F(3,90)=0.628, p=0.60, R^{2}=0.02$ & & \\
\hline
\end{tabular}

$B M I$ body mass index, $C$ cortisol, $H R$ heart rate, $T$ testosterone

not reveal any significant effects. All models tested were non-significant $(p>0.14)$ and weak, explaining no more than $8 \%$ of the outcome variance. ${ }^{1}$

\section{Discussion}

This short report documents the first attempt to investigate, experimentally via an exercise intervention, the interplay between acute $\mathrm{T}$ dynamics and general mating strategies among men. Contrary to our hypotheses, neither the $\mathrm{T}$ change nor its interaction with $\mathrm{C}$ predicted state mating preference, which was generally stable before and after exercise testing. This stability is unlikely to be a measurement artefact, as similar measures have proven

\footnotetext{
$\overline{1}$ Because $\mathrm{T}$ and $\mathrm{C}$ levels show diurnal variation, we repeated each model with study start time included as a covariate $(n=78)$. No qualitative changes were observed.
}

sensitivity to track subtle changes in mating strategy following brief priming interventions (Thomas and StewartWilliams 2018).

The sprint exercise intervention increased $\mathrm{T}$ by around $10 \%$. This was a modest $\mathrm{T}$ rise, much smaller than anticipated based on the $25 \%$ increase observed previously among healthy untrained men (Crewther et al. 2014) and much smaller than the $1300 \%+$ increases seen in some single-dose T administration studies (e.g., Nave et al. 2018). However, supraphysiological levels of $\mathrm{T}$ concentration are not necessary to observe $\mathrm{T}$ effects on mating behaviour. Bird et al. (2016), for example, found that a 52\% increase in $\mathrm{T}$ was enough to increase preference for facial femininity in short-term, relative to long-term, mating contexts by $8 \%$ - a medium sized effect $(d=0.49)$. The present study also highlighted the presence of large intragroup variation in $\mathrm{T}$ reactivity, ranging from a $51 \%$ decline up to a $187 \%$ increase. Therefore, we suggest that interventions producing larger and more consistent $\mathrm{T}$ increases, like those elicited by 
pharmacological interventions, may be required to produce detectable changes in mating strategy.

The inability of exercise to promote covarying responses does not necessarily preclude a predictive role for $\mathrm{T}$, but it does limit any casual claims. Nevertheless, we found no evidence that acute $\mathrm{T}$ changes are related to mating preferences, at least within the current format. This work focused on a sample of men for both practical (i.e., cost) and theoretical reasons (i.e., the inconsistent relationship between $\mathrm{T}$ and mating-related behaviour in women; Carré et al. 2013; Kuepper et al. 2010; Rejeski et al. 1990). Future investigations could compare both men and women to allow sex differences to be examined rather than inferred (Stewart-Williams and Thomas 2013), particularly as women often exhibit similar $\mathrm{T}$ responses to men, expressed as a percentage from baseline, but at a lower $\mathrm{T}$ concentrations (Crewther et al. 2016). A more robust design, coupled with measures of individuality and personality, would also allow us to consider potential moderating factors, such as relationship status and context (e.g., the presence/absence of female confederates).

This pilot study is limited by other methodological factors, namely, the pre- and post-test design, use of a stimulus likely to elicit other physiological responses, and the lack of a control group. The testing of participants in the morning might also explain our inability to induce a larger $\mathrm{T}$ rise and the lack of a $\mathrm{C}$ response, as higher $\mathrm{C}$ levels at the start of the day may have led to a ceiling effect during exercise. However, controlling for time of day did not affect any outcome, nor did it predict the exercise-induced changes in T or C. Study replication (in the afternoon) might provide some novel insight around diurnal variability and its role in regulating both hormones and mate-choice behaviours, and response flexibility following brief exposure to an ecological stimulus. Because studies which investigate how hormones affect human behaviour are often underpowered (e.g., Geniole et al. 2019; Thomas et al. 2021), such replications would benefit from larger samples, providing enough power to detect small effects.

In summary, a brief bout of sprint exercise caused a modest increase in $\mathrm{T}$ concentration, but this change did not covary, or predict, state desire for short-term and long-term mating. Consideration of $\mathrm{C}$ change, as a moderating factor, did not modify our predictions. Larger and more consistent increases in $\mathrm{T}$, such as those afforded by pharmacological interventions, may be required to initiate strategy change.

Authors' Contributions Conceptualization: Andrew G. Thomas, Blair T. Crewther; Methodology: Andrew G. Thomas, Marta Kowal, Blair T. Crewther; Formal analysis and investigation: Andrew G. Thomas, Marta Kowal, Piotr Sorokowski, Agnieszka Żelaźniewicz, Judyta Nowak, Sylwester Orzechowski, Blair T. Crewther, Andrew G. Thomas, Blair T. Crewther; Writing-original draft preparation:
Andrew G. Thomas, Blair T. Crewther; Writing-review and editing: Andrew G. Thomas, Marta Kowal, Piotr Sorokowski, Blair T. Crewther; Funding acquisition: Marta Kowal, Piotr Sorokowski; Resources: Marta Kowal, Piotr Sorokowski; Supervision: Marta Kowal, Piotr Sorokowski.

Funding The study was made possible by the funds from the University of Wroclaw, Poland.

Data Availability Data and materials are available from the first author upon request.

Code Availability Analysis was conducted using SPSS.

\section{Compliance with Ethical Standard}

Conflicts of Interest The authors declare that they have no conflict of interest.

Ethics Approval The study received ethical approval from the Institutional Ethics Committee at the Institute of Psychology at the University of Wroclaw, Poland.

Consent to Participate Informed consent was obtained from all individual participants included in the study.

Consent for Publication Patients signed informed consent regarding publishing their data and photographs.

Open Access This article is licensed under a Creative Commons Attribution 4.0 International License, which permits use, sharing, adaptation, distribution and reproduction in any medium or format, as long as you give appropriate credit to the original author(s) and the source, provide a link to the Creative Commons licence, and indicate if changes were made. The images or other third party material in this article are included in the article's Creative Commons licence, unless indicated otherwise in a credit line to the material. If material is not included in the article's Creative Commons licence and your intended use is not permitted by statutory regulation or exceeds the permitted use, you will need to obtain permission directly from the copyright holder. To view a copy of this licence, visit http://creativecommons. org/licenses/by/4.0/.

\section{References}

Al-Shawaf, L., Lewis, D. M., Ghossainy, M. E., \& Buss, D. M. (2019). Experimentally inducing disgust reduces desire for short-term mating. Evolutionary Psychological Science, 5(3), 267-275.

Arnocky, S., Woodruff, N., \& Schmitt, D. P. (2016). Men's sociosexuality is sensitive to changes in mate availability. Personal Relationships, 23(1), 172-181.

Bird, B. M., Welling, L. L., Ortiz, T. L., Moreau, B. J., Hansen, S., Emond, M., ... \& Carre, J. M. (2016). Effects of exogenous testosterone and mating context on men's preferences for female facial femininity. Hormones and Behavior, 85, 76-85.

Carré, J. M., Campbell, J. A., Lozoya, E., Goetz, S. M., \& Welker, K. M. (2013). Changes in testosterone mediate the effect of winning on subsequent aggressive behaviour. Psychoneuroendocrinology, 38(10), 2034-2041. 
Crewther, B. T., Kilduff, L. P., \& Cook, C. (2014). Trained and untrained males show reliable salivary testosterone responses to a physical stimulus, but not a psychological stimulus. Journal of Endocrinological Investigation, 37(11), 1065-1072.

Crewther, B. T., Kilduff, L. P., Finn, C., Scott, P., \& Cook, C. J. (2016). Salivary testosterone responses to a physical and psychological stimulus and subsequent effects on physical performance in healthy adults. Hormones, 15(2), 248-255.

Crewther, B. T., Thomas, A. G., Stewart-Williams, S., Kilduff, L. P., \& Cook, C. J. (2017). Is salivary cortisol moderating the relationship between salivary testosterone and hand-grip strength in healthy men? European Journal of Sport Science, 17(2), 188-194.

Geniole, S., Bird, B., McVittie, J., Purcell, R., Archer, J., \& Carré, J. (2019). Is testosterone linked to human aggression? (p. 104644). A Meta-Analytic Examination of the Relationship between Baseline: Dynamic, and manipulated testosterone on human aggression. hormones and behavior.

Gray, P. B., Jeffrey-Yang, C.-F., \& Pope, H. G. (2006). Fathers have lower salivary testosterone levels than unmarried men and married non-fathers in Beijing, China. Proceedings of the Royal Society B: Biological Sciences, 273(1584), 333-339.

Gray, P. B., Straftis, A. A., Bird, B. M., McHale, T. S., \& Zilioli, S. (2020). Human reproductive behavior, life history, and the challenge hypothesis: a 30-year review, retrospective and future directions. Hormones and Behavior, 123, 104530.

Grebe, N. M., Del Giudice, M., Thompson, M. E., Nickels, N., Ponzi, D., Zilioli, S., ... \& Gangestad, S. W. (2019). Testosterone, cortisol, and status-striving personality features: a review and empirical evaluation of the dual hormone hypothesis. Hormones and Behavior, 109, 25-37.

Grebe, N. M., Sarafin, R. E., Strenth, C. R., \& Zilioli, S. (2019). Pairbonding, fatherhood, and the role of testosterone: a meta-analytic review. Neuroscience \& Biobehavioral Reviews, 98, 221-233.

Kilduff, L. P., Hopp, R. N., Cook, C. J., Crewther, B. T., \& Manning, J. T. (2013). Digit ratio (2d: 4d), aggression, and testosterone in men exposed to an aggressive video stimulus. Evolutionary Psychology, 11(5), 147470491301100500.

Kowal, M., Sorokowski, P., Żelaźniewicz, A., Nowak, J., Orzechowski, S., Żurek, G., ... \& Danek, N. (2020). No relationship between the digit ratios (2d: $4 \mathrm{~d})$ and salivary testosterone change: study on men under an acute exercise. Scientific Reports, 10(1), 1-8.

Kuepper, Y., Alexander, N., Osinsky, R., Mueller, E., Schmitz, A., Netter, P., \& Hennig, J. (2010). Aggression-interactions of serotonin and testosterone in healthy men and women. Behavioural Brain Research, 206(1), 93-100.

Mehta, P. H., \& Josephs, R. A. (2010). Testosterone and cortisol jointly regulate dominance: evidence for a dual-hormone hypothesis. Hormones and Behavior, 58(5), 898-906.

Nave, G., Nadler, A., Dubois, D., Zava, D., Camerer, C., \& Plassmann, H. (2018). Single-dose testosterone administration increases men's preference for status goods. Nature Communications, 9(1), 1-8.

Nave, G., Nadler, A., Zava, D., \& Camerer, C. (2017). Single-dose testosterone administration impairs cognitive reflection in men. Psychological Science, 28(10), 1398-1407.

Rejeski, W. J., Parker, P. E., Gagne, M., \& Koritnik, D. R. (1990). Cardiovascular and testosterone responses to contested dominance in women. Health Psychology, 9(1), 35-47.

Ronay, R., \& von Hippel, W. (2010). The presence of an attractive woman elevates testosterone and physical risk taking in young men. Social Psychological and Personality Science, 1(1), 57-64.

Stewart-Williams, S., \& Thomas, A. G. (2013). The ape that kicked the hornet's nest: response to Commentaries on "The ape that thought it was a peacock." Psychological Inquiry, 24(3), 248-271.

Thomas, A. G., Armstrong, S. L., Stewart-Williams, S., \& Jones, B. C. (2021). Current fertility status does not predict sociosexual attitudes and desires in normally ovulating women. Evolutionary Psychology, 19(1), 1474704920976318.

Thomas, A. G., \& Stewart-Williams, S. (2018). Mating strategy flexibility in the laboratory: preferences for long- and short-term mating change in response to evolutionarily relevant variables. Evolution and Human Behavior, 39(1), 82-93.

Zilioli, S., \& Bird, B. M. (2017). Functional significance of men's testosterone reactivity to social stimuli. Frontiers in Neuroendocrinology, 47, 1-18.

Publisher's Note Springer Nature remains neutral with regard to jurisdictional claims in published maps and institutional affiliations. 